\title{
PAPER
}

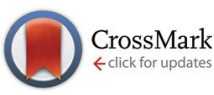

Cite this: Food Funct., 2016, 7, 2338

\section{Minimally processed foods are more satiating and less hyperglycemic than ultra-processed foods: a preliminary study with 98 ready-to-eat foods}

\begin{abstract}
Anthony Fardet*
Beyond nutritional composition, food structure is increasingly recognized to play a role in food health potential, notably in satiety and glycemic responses. Food structure is also highly dependent on processing conditions. The hypothesis for this study is, based on a data set of 98 ready-to-eat foods, that the degree of food processing would correlate with the satiety index (SI) and glycemic response. Glycemic response was evaluated according to two indices: the glycemic index (Gl) and a newly designed index, the glycemic glucose equivalent (GGE). The GGE indicates how a quantity of a certain food affects blood glucose levels by identifying the amount of food glucose that would have an effect equivalent to that of the food. Then, foods were clustered within three processing groups based on the international NOVA classification: (1) raw and minimally processed foods; (2) processed foods; and (3) ultra-processed foods. Ultra-processed foods are industrial formulations of substances extracted or derived from food and additives, typically with five or more and usually many (cheap) ingredients. The data were correlated by nonparametric Spearman's rank correlation coefficient on quantitative data. The main results show strong correlations between GGE, SI and the degree of food processing, while Gl is not correlated with the degree of processing. Thus, the more food is processed, the higher the glycemic response and the lower its satiety potential. The study suggests that complex, natural, minimally and/or processed foods should be encouraged for consumption rather than highly unstructured and ultra-processed foods when choosing weakly hyperglycemic and satiating foods.
\end{abstract}

Received 26th January 2016 Accepted 23rd April 2016

DOI: 10.1039/c6fo00107f

www.rsc.org/foodfunction western-type diets) increase the risk of type 2 diabetes by 41 to $44 \% .^{2,4}$ These diets are usually high in animal products and/or ultra-processed foods that are high in energy and low in protective compounds. Beyond conventional food groups, these results suggest that the degree of food processing also comes into play when assessing the risk of type 2 diabetes. ${ }^{11}$

Within the same food group, there are indeed foods with diverse health values according to the technological processes applied. ${ }^{11}$ Thus, ready-to-eat breakfast cereals for adults, such as muesli, and those for children, such as extruded cereals enriched with sugars and fat, have very different nutritional values. ${ }^{12}$ Moreover, among 39765 men and 157463 women in the Health Professionals Follow-up Study and the Nurses' Health Study I and II, high intake of brown rice was associated with an 11\% lower relative risk of type 2 diabetes, whereas high consumption of white rice was associated with a $17 \%$ higher relative risk of type 2 diabetes. ${ }^{13}$ In these two examples, the degree of processing is likely to make the difference from a nutritional point of view, not cereal as a botanical group.

Based on the NOVA classification ranking foods into 4 groups (see groups lines below) according to their extent of processing, other studies have also shown that ultra-processed food as a whole (Group 4), are nutritionally inferior to the com- 
bination of raw and minimally processed foods (Group 1), culinary ingredients (Group 2) and processed foods (Group 3), both for macro and micro nutrients. ${ }^{14-18}$

Depending on the degree of processing, food can also register differently on the glycemic index and have a different satiating effect, ${ }^{19-21}$ as shown, for example, with raw, processed (cooked, blended or refined) apples and carrots. ${ }^{22-24}$ This suggests that the more food is deconstructed, the higher its glycemic response and the less satiating it is, but because data on the subject remain scarce, this effect needs to be confirmed for a larger number of foods.

As suggested above, any food has the potential to change postprandial blood glucose after consumption. Until recently, the glycemic index (GI) has been mainly used ${ }^{25}$ and more recently the glycemic load, which is related to the amount of food consumed. ${ }^{26,27}$ However, ten years ago a new concept was developed and validated by Monro et al: the glycemic glucose equivalent (GGE). ${ }^{28}$ It indicates how a quantity of a food affects blood glucose levels by showing the equivalent effect of ingested food glucose. Thus, if a serving of food contributes 15 GGE ( $\mathrm{g}$ per $100 \mathrm{~g}$ ), it has the same effect on the body as consuming 15 grams of glucose. Therefore, GGE behaves like a compound of the food, and the relative glycemic impact is the GGE consumption responsible for a glycemic response. ${ }^{28}$ The relative glycemic impact therefore differs from the GI because it refers to the food and depends on the consumption of the food (i.e., does not need to be restricted to equi-carbohydrate comparison), whereas the GI refers to carbohydrates only and is a unitless index that does not account for food intake. Moreover, because the consumption of the GGE is a function of the consumption of food, it can be used quantitatively to give a direct measurement of the glycemic impact of an amount of food on the body rather than just carbohydrates. ${ }^{28}$ By releasing the constraint of equivalence in carbohydrates and with regard to its reactivity to food intake, the GGE has significant advantages over the GI and carbohydrate content in the management of blood glucose. Thus, the content in the GGE should allow individual objectives of meals to be clarified, realistically, according to a glycemic effect once the individual GGE tolerance is established by measuring the blood glucose response to a known consumption of GGE. ${ }^{29}$

Otherwise, the satiety potential is often an overlooked aspect of food. A feeling of prolonged satiety is beneficial because it discourages snacking between meals, which is often of refined foods, rich in energy and with a high GI. Being able to choose foods with high satiety potential may therefore be an advantage for preventing diabetes and obesity. However, data on the satiety potential of foods are scarce. ${ }^{19}$

Therefore, considering the possible role of processing in the satiety potential and glycemic impact of foods, I hypothesized, based on a much greater number of foods $(n=98$ ready-to-eat foods), that the degree of food processing would correlate with satiety potential and glycemic response. Because a higher prevalence of chronic diseases, e.g., dyslipidemia, ${ }^{30}$ metabolic syndrome, ${ }^{31}$ obesity, ${ }^{32,33}$ and cardiovascular diseases, ${ }^{34}$ is associated with regular and high consumption of ultra-processed foods, the foods in this study were classified, not according to their botanical (i.e., fruits, vegetables, grains and seeds) or animal (e.g., red and white meats, dairy products) affiliation, but according to the degree of their processing according to the NOVA classification. ${ }^{35}$ The objective of this study was to test the correlations among the degree of food processing, satiety index and glycemic impact.

\section{Materials and methods}

\section{Food selection}

A table of 1224 foods and food ingredients consumed by diabetic individuals has been compiled by the French Paramedical Society of Diabetes (SFD Paramédical, Paris, France). These foods come from all conventional food groups, including beverages, snacks, ready-to-eat meals, fats, seasonings, baked goods, and confectionaries. Within them, 98 foods were selected based on the data available in the literature for their glycemic impact (GGE and GI) and/or satiety potential (Tables 1-3).

\section{Degree of processing}

For classification according to the degree and purpose of food processing, we relied on the work of the Brazilian team of Monteiro et al., who developed the NOVA classification of foods based on the extent to which they are processed. ${ }^{35,36}$

The international NOVA classification clusters foods into 4 groups according to the degree of processing from the least to the most drastic transformation. ${ }^{14,37,38}$ Briefly, as synthesized from Monteiro et al: ${ }^{38}$ (1) raw and minimally processed food: unprocessed foods are the parts of the animals collected immediately after slaughter and the parts of plant products after harvest or collection. Minimally processed foods are unprocessed foods subject to a transformation, especially a change in their physical properties that does not substantially alter the nutritional properties or uses of the foods. These processes are used to extend the storage time for unprocessed foods and often to reduce the time and effort required for their preparation. (2) Culinary ingredients: these are substances obtained directly from group 1 foods or from nature by processes such as pressing, refining, grinding, milling, and spray drying. The purpose of processing here is to make products used in home and restaurant kitchens to prepare, season and cook group 1 foods and to make with them varied and enjoyable hand-made dishes, soups and broths, breads, preserves, salads, drinks, desserts and other culinary preparations. Group 2 items are rarely consumed in the absence of group 1 foods. (3) Processed foods: these are relatively simple products made by adding sugar, oil, salt or other group 2 substances to group 1 foods. Most processed foods have two or three ingredients. Processes include various preservation or cooking methods, and, in the case of breads and cheese, nonalcoholic fermentation. The main purpose of the manufacture of processed foods is to increase the durability of Group 1 foods, or to modify or enhance their sensory qualities. (4) Ultra-processed foods: these are industrial formulations of 
Table 1 Satiety index, available carbohydrates and glycemic potential of raw and minimally processed foods

\begin{tabular}{|c|c|c|c|c|c|c|}
\hline \multirow[b]{2}{*}{ Foods } & \multirow[b]{2}{*}{$\begin{array}{l}\text { Satiety index } \\
(\text { means } \pm \mathrm{SEM})^{a}\end{array}$} & \multirow[b]{2}{*}{$\begin{array}{l}\text { Serving } \\
(\mathrm{g})\end{array}$} & \multirow[b]{2}{*}{$\begin{array}{l}\text { Available carbohydrates }{ }^{b} \\
\text { (g per } 100 \mathrm{~g} \text { ) }\end{array}$} & \multicolumn{2}{|c|}{$\begin{array}{l}\text { Relative glycemic } \\
\text { impact }\end{array}$} & \multirow[b]{2}{*}{$\begin{array}{l}\text { Glycemic index } \\
{(\text { means } \pm \mathrm{SEM})^{d}}\end{array}$} \\
\hline & & & & $\begin{array}{l}\mathrm{GGE} / \\
100 \mathrm{~g}^{c}\end{array}$ & $\begin{array}{l}\text { GGE/ } \\
\text { serving }\end{array}$ & \\
\hline Red meat and pork & $176 \pm 50$ & & Traces & & & \\
\hline Fish & $225 \pm 30$ & & Traces & & & \\
\hline Egg & $150 \pm 31$ & & 0.5 & & & \\
\hline Bulgur, cooked & & 150 & 18.6 & 8 & 12 & $48 \pm 2$ \\
\hline Pasta, cooked & $119 \pm 35$ & 180 & 29.7 & 10 & 18 & $44 \pm 3$ \\
\hline Wholemeal pasta, cooked & $188 \pm 45$ & 180 & 26.8 & 10 & 17.8 & $37 \pm 5$ \\
\hline Fava beans, cooked & & 80 & 6.1 & 7 & 5.6 & $79 \pm 16$ \\
\hline White beans, cooked & $168 \pm 42$ & 150 & 13.6 & 6 & 9 & $29 \pm 9$ \\
\hline Kidney beans, cooked & & 150 & 14.4 & 4 & 6 & $28 \pm 4$ \\
\hline Yam, raw or cooked & & 150 & 27.9 & 10 & 15 & $37 \pm 8$ \\
\hline Lentils, cooked & $133 \pm 28$ & 150 & 16.6 & 4 & 6 & $30 \pm 4$ \\
\hline Sweet corn on the cob, cooked & & 80 & 16.4 & 11 & 8.8 & $54 \pm 4$ \\
\hline Cassava & & 100 & 35.0 & 15 & 15 & 46 \\
\hline Split peas, cooked & & 150 & 14.0 & 7 & 10.5 & 32 \\
\hline Potato, boiled in water & $323 \pm 51$ & 150 & 15.8 & 10 & 15 & $50 \pm 9$ \\
\hline Instant mashed potatoes, reconstituted & & 150 & 14.6 & 12 & 18 & $85 \pm 3$ \\
\hline White rice, cooked & $138 \pm 31$ & 150 & 28.7 & 10 & 15 & $64 \pm 7$ \\
\hline Brown rice, cooked & $132 \pm 35$ & 150 & 31.7 & 16 & 24 & $55 \pm 5$ \\
\hline Beetroot, raw or cooked & & 80 & 7.2 & 7 & 5.6 & $64 \pm 16$ \\
\hline Carrot, raw or cooked & & 80 & 6.6 & 3 & 2.4 & $47 \pm 16$ \\
\hline Turnip, raw or cooked & & 80 & 3.1 & 3 & 2.4 & 72 \\
\hline Parsnip, raw or cooked & & 80 & 17.0 & 12 & 9.6 & $97 \pm 19$ \\
\hline Green peas, cooked & & 80 & 8.3 & 2 & 1.6 & $48 \pm 5$ \\
\hline Pumpkin, cooked & & 80 & 1.9 & 3 & 2.4 & $75 \pm 9$ \\
\hline Milk (whole, semi-skimmed and skimmed) & & 250 & 5.0 & 1 & 2.5 & $27 \pm 4$ \\
\hline Plain yogurt & $88 \pm 23$ & 200 & 4.6 & 2 & 3.3 & $36 \pm 4$ \\
\hline Muesli & $100 \pm 23$ & 30 & 61.5 & 28 & 8.4 & $49 \pm 9$ \\
\hline Apricot & & 120 & 9.0 & 5 & 6 & 57 \\
\hline Pineapple & & 120 & 11.0 & 8 & 9.6 & $59 \pm 8$ \\
\hline Banana & $118 \pm 27$ & 120 & 20.5 & 13 & 15.6 & $52 \pm 4$ \\
\hline Cherries & & 120 & 14.2 & 3 & 3.6 & 22 \\
\hline Strawberries & & 120 & 4.1 & 3 & 3.6 & 40 \\
\hline Kiwi fruit & & 120 & 9.4 & 5 & 6 & $53 \pm 6$ \\
\hline Melon & & 120 & 6.5 & 4 & 4.8 & $65 \pm 9$ \\
\hline Orange & $202 \pm 34$ & 120 & 8.3 & 4 & 4.8 & $42 \pm 3$ \\
\hline Grapefruit & & 120 & 6.2 & 1 & 1.2 & 25 \\
\hline Watermelon & & 120 & 7.3 & 4 & 4.8 & $72 \pm 13$ \\
\hline Peach, nectarine & & 120 & 11.3 & 3 & 3.6 & $42 \pm 14$ \\
\hline Pear & & 120 & 10.8 & 5 & 6 & 33 \\
\hline Apple & $197 \pm 32$ & 120 & 11.3 & 4 & 4.8 & $38 \pm 2$ \\
\hline Damson plum & & 120 & 9.6 & 5 & 6 & $39 \pm 15$ \\
\hline Black grape & $162 \pm 32$ & 120 & 12.1 & 7 & 8.4 & $46 \pm 3$ \\
\hline Dried apricot & & 60 & 53.0 & 15 & 9 & $31 \pm 1$ \\
\hline Dried dates & & 60 & 62.5 & 70 & 42 & $103 \pm 21$ \\
\hline Dried figs & & 60 & 50.4 & 33 & 19.8 & $61 \pm 6$ \\
\hline Prunes & & 60 & 52.3 & 13 & 7.8 & $29 \pm 4$ \\
\hline Raisins & & 60 & 66.4 & 46 & 27.6 & $64 \pm 11$ \\
\hline Carrot juice & & 250 & 5.1 & 3 & 7.5 & $43 \pm 3$ \\
\hline Tomato juice & & 250 & 3.9 & 2 & 5 & $38 \pm 4$ \\
\hline Fresh orange juice & & 250 & 15.0 & 5 & 12.5 & $50 \pm 4$ \\
\hline
\end{tabular}

SEM, standard error of the means. ${ }^{a}$ Satiety index of white bread $=100 \%$; data from Holt et al. ${ }^{19}$ For information, the sample size $(n$-value for means) for each food can be found in the table by Holt et al. ${ }^{19 b}$ Data were collected primarily from the 2013 French Ciqual database (available online at: https://pro.anses.fr/tableciqual/index.htm); the rest were taken directly from the product labels of specific brands. ${ }^{c}$ Data from Monro. ${ }^{44}$ ${ }^{d}$ Glycemic index of glucose $=100$; data for glycemic index from Foster-Powell et al. ${ }^{20}$ For information, the sample size ( $n$-value for means) for each food can be found in the table by Foster-Powell et al. ${ }^{20}$ When values were given without SEM, this means that they correspond to only one measurement.

substances extracted or derived from food and additives, typically with five or more and usually many (cheap) ingredients. Such ingredients often include those also used in processed foods, such as sugar, oils, fats, salt, anti-oxidants, stabilizers, and preservatives. Ingredients only found in ultra-processed products include substances not commonly used in culinary preparations, and additives whose purpose is to imitate sensory qualities of Group 1 foods or of culinary preparations of these foods, or to disguise undesirable sensory qualities of the final product. Group 1 foods are a small proportion of or 
Table 2 Satiety index, available carbohydrates and glycemic potential of processed foods

\begin{tabular}{|c|c|c|c|c|c|c|}
\hline & $\begin{array}{l}\text { Satiety index } \\
\left(_{\text {means } \pm \mathrm{SEM})^{a}}\right.\end{array}$ & $\begin{array}{l}\text { Serving } \\
(\mathrm{g})\end{array}$ & $\begin{array}{l}\text { Available carbohydrates } \\
\text { (g per } 100 \mathrm{~g} \text { ) }\end{array}$ & \multicolumn{2}{|c|}{ Relative glycemic impact } & $\begin{array}{l}\text { Glycemic index } \\
(\text { means } \pm \mathrm{SEM})^{d}\end{array}$ \\
\hline Fried potatoes, home-cooked & $116 \pm 35$ & 150 & 30.0 & 21 & 31.5 & 75 \\
\hline Lebanese hummus & & 30 & 9.3 & 0 & 0 & $6 \pm 4$ \\
\hline Minestrone & & 250 & 4.8 & 3 & 7.5 & $39 \pm 3$ \\
\hline Cheese & $146 \pm 28$ & & $0-3.0$ & & & \\
\hline Rye bread & & 30 & 49.8 & 25 & 7.5 & $58 \pm 6$ \\
\hline Pita bread & & 30 & 53.4 & 33 & 9.9 & 57 \\
\hline Pears in syrup & & 120 & 13.9 & 4 & 4.8 & 44 \\
\hline Peanuts, roasted, salted & & 50 & 9.7 & 2 & 1 & $14 \pm 8$ \\
\hline Cashew nuts, grilled, salted & & 50 & 21.8 & 5 & 2.5 & $22 \pm 5$ \\
\hline
\end{tabular}

SEM, standard error of the means. ${ }^{a}$ Satiety index of white bread $=100 \%$; data given by Holt $e t$ al. ${ }^{19}$ For information, the sample size $(n$-value for means) for each food can be found in the table by Holt et al. ${ }^{19 b}$ Data were collected primarily from the 2013 French Ciqual database (available online at: https://pro.anses.fr/tableciqual/index.htm); the rest were taken directly from the product labels of specific brands. ${ }^{c}$ Data from Monro. ${ }^{44}$ ${ }^{d}$ Glycemic index of glucose $=100$; data for glycemic index from Foster-Powell et al. ${ }^{20}$ For information, the sample size ( $n$-value for means) for each food can be found in the table by Foster-Powell et al. ${ }^{20}$ When values were given without SEM, this means that they correspond to only one measurement.

are even absent from ultra-processed products. The main purpose of industrial ultra-processing is to create products that are ready to eat, to drink or to heat, liable to replace both unprocessed or minimally processed foods that are naturally ready to consume, such as fruits and nuts, milk and water, and freshly prepared drinks, dishes, desserts and meals. Common attributes of ultra-processed products are hyperpalatability, sophisticated and attractive packaging, multimedia and other aggressive marketing to children and adolescents, health claims, high profitability, and branding and ownership by transnational corporations". ${ }^{38}$

According to NOVA, consumption of Group 4 ultra-processed food predicts overall diet quality, obesity and other chronic diseases, while Group 1, 2 and 3 taken together are the basis of a healthy diet. Indeed, epidemiological studies have provided evidence that foods within group 4 are primarily responsible for the dramatic increase in the prevalence of obesity, metabolic syndrome and dyslipidemia. ${ }^{30-33,39-43}$

This study was based on ready-to-eat foods only. Therefore, culinary ingredients from Group 2 were not considered. Then, the 98 foods were ranked within Groups 1, 3 and 4 based on NOVA descriptions. Finally, for the purpose of this study, food groups were renamed as follow: Group 1, raw and minimally processed foods (MPF, $n=49$ foods; Table 1); Group 2, processed foods (PF, $n=12$ foods; Table 2); and Group 3, ultraprocessed foods (UPF, $n=37$; Table 3 ).

\section{The glycemic potential}

Approximate GGE values may be obtained from: ${ }^{28,29}$

$$
\mathrm{GGE}=(\% \text { of available carbohydrates } / 100) \times \mathrm{GI}
$$

and:

Relative glycemic impact $=$ food weight consumed

$$
\times \text { GGE per } g
$$

GGE values may be also subject to error imported from currently available carbohydrate values. ${ }^{28}$

In this study, GGE was connected with the GI and the degree of processing using tables for the $\mathrm{GGE}^{44}$ and the GI. ${ }^{20}$ GGE values not available in table by Monro were calculated from formula (1) (see above).

\section{The satiety potential}

The only available data are the satiety index (SI) given for 38 foods grouped into six categories: fruits (average SI = 170), bread products (average SI $=85$ ), snacks and confectionery (average SI $=100$ ), starchy foods (average SI = 166), foods high in protein (average SI $=166$ ) and ready-to-eat breakfast cereals (average SI = 134), with white bread used as a reference (average SI = 100). ${ }^{19}$ Briefly, SI score was calculated by dividing the area under the satiety response curve for the test food by the group mean satiety area under curve for white bread and multiplying by 100 .

In this study, the SI was connected with the glycemic response (GGE and GI) and the degree of processing using a table compiled by Holt et al. ${ }^{19}$

\section{Statistical analyses}

The data for the GI, GGE, SI and degree of processing were correlated using the nonparametric Spearman's rank correlation coefficient $\left(R_{\mathrm{s}}\right)$ for quantitative data (BiostaTGV, based on $\mathrm{R}$ software, available online at: http://marne.u707.jussieu.fr/ biostatgv/?module=tests/spearman). This web tool was developed in 2000 by the Institute Pierre Louis of Epidemiology and Public Health, which is affiliated with INSERM, and the Pierre \& Marie Curie University. A $P$ value $<0.05$ indicates a significant correlation.

For calculations, the qualitative data for the degree of processing were converted into quantitative data as follows: $\mathrm{MPF}=1 ; \mathrm{PF}=2 ; \mathrm{UPF}=3$, with " 3 " being more processed than 
Table 3 Satiety index, available carbohydrates and glycemic potential of ultra-processed foods

\begin{tabular}{|c|c|c|c|c|c|c|}
\hline \multirow[b]{2}{*}{ Foods } & \multirow[b]{2}{*}{$\begin{array}{l}\text { Satiety index } \\
(\text { means } \pm \text { SEM })^{a}\end{array}$} & \multirow[b]{2}{*}{$\begin{array}{l}\text { Serving } \\
(\mathrm{g})\end{array}$} & \multirow[b]{2}{*}{$\begin{array}{l}\text { Available carbohydrates }{ }^{b} \\
\text { (g per } 100 \mathrm{~g} \text { ) }\end{array}$} & \multicolumn{2}{|c|}{$\begin{array}{l}\text { Relative glycemic } \\
\text { impact }\end{array}$} & \multirow[b]{2}{*}{$\begin{array}{l}\text { Glycemic index } \\
{\text { (means } \pm \text { SEM })^{d}}\end{array}$} \\
\hline & & & & $\begin{array}{l}\mathrm{GGE} / \\
100 \mathrm{~g}^{c}\end{array}$ & $\begin{array}{l}\text { GGE/ } \\
\text { serving }\end{array}$ & \\
\hline Pizza & & 100 & 27.7 & 8 & 8 & 51 \\
\hline Chicken McNuggets & & 100 & 17.0 & 7 & 21 & $46 \pm 4$ \\
\hline Pancake & & 80 & 28.0 & 19 & 15.2 & $67 \pm 5$ \\
\hline Fish'n dips & & 100 & 31.2 & 8 & 8 & $38 \pm 6$ \\
\hline Ravioli with tomato sauce & & 180 & 13.5 & 9 & 16.2 & $39 \pm 1$ \\
\hline Tomato soup & & 250 & 2.5 & 3 & 7.5 & $38 \pm 9$ \\
\hline Sweetened condensed milk & & 250 & 55.9 & 33 & 82.5 & $61 \pm 6$ \\
\hline Croissant (packaged) & $47 \pm 17$ & 57 & 47.7 & 26 & 14.8 & 67 \\
\hline Kellogg's all-bran fibre plus cereal & $151 \pm 30$ & 30 & 48.0 & 17 & 5.1 & $42 \pm 5$ \\
\hline Kellogg's coco pops cereal & & 30 & 85.0 & 67 & 20.1 & 77 \\
\hline Kellogg's corn flakes & $118 \pm 19$ & 30 & 78.3 & 69 & 20.7 & $81 \pm 3$ \\
\hline Kellogg's special K cereal & $116 \pm 27$ & 30 & 75.0 & 38 & 11.4 & $84 \pm 12$ \\
\hline Kellogg's Frosties & & 30 & 87.0 & 49 & 14.7 & 55 \\
\hline $\begin{array}{l}\text { Balisto bar (with fruits, honey, } \\
\text { milk and muesli) }\end{array}$ & & 30 & 56.0 & 35 & 10.5 & 61 \\
\hline Chocolate and cereal snack bar & & 30 & 65.7 & 36 & 10.8 & 50 \\
\hline Chocolate cookies & $120 \pm 24$ & & 61.3 & & & \\
\hline Cookies & & 25 & 66.2 & 38 & 9.5 & $59 \pm 2$ \\
\hline Mini sponge cake & $65 \pm 17$ & 63 & 60.7 & 28 & 17.6 & $46 \pm 6$ \\
\hline Shortbread & & 25 & 64.8 & 38 & 9.5 & $64 \pm 8$ \\
\hline Ice cream & $96 \pm 26$ & 50 & 33.1 & 14 & 7 & $61 \pm 7$ \\
\hline Fruit or flavored yogurts & & 200 & 16.3 & 5 & 10 & $33 \pm 7$ \\
\hline Fruitcake & $65 \pm 17$ & & 55.7 & & & \\
\hline Doughnuts & $68 \pm 20$ & & 42.0 & & & \\
\hline Savoie sponge cake & & 63 & 68.3 & 26 & 16.4 & $46 \pm 6$ \\
\hline Chocolate muffin with bilberries & & 57 & 48.7 & 27 & 15.4 & 59 \\
\hline Fruit jelly or jam & & 30 & 60.0 & 33 & 9.9 & $51 \pm 10$ \\
\hline Dragees (chocolate and almond) & $118 \pm 26$ & & 52.0 & & & \\
\hline M\&M’s & & 30 & 60.1 & 17 & 5.1 & $33 \pm 3$ \\
\hline Mars bar & $70 \pm 25$ & 60 & 79.2 & 41 & 24.6 & $65 \pm 3$ \\
\hline Sweetened popcorn & $154 \pm 40$ & 20 & 62.0 & 45 & 9 & $72 \pm 17$ \\
\hline Snickers bar & & 60 & 60.2 & 23 & 13.8 & $55 \pm 14$ \\
\hline Chocolate milk & & 50 & 10.0 & 3 & 1.5 & $43 \pm 3$ \\
\hline Sweetened cocoa beverage & & & 10.0 & 2 & & 36 \\
\hline Sodas & & & 10.0 & 7 & & 63 \\
\hline Chips & $91 \pm 27$ & 50 & 50.0 & 26 & 13 & $54 \pm 3$ \\
\hline Tortilla chips, salted & & 50 & 55.2 & 39 & 19.5 & 52 \\
\hline
\end{tabular}

SEM, standard error of the means. ${ }^{a}$ Satiety index of white bread $=100 \%$; data from Holt et al. ${ }^{19}$ For information, the sample size $(n$-value for means) for each food can be found in the table by Holt et al. ${ }^{19} b$ Data were collected primarily from the 2013 French Ciqual database (available online at: https://pro.anses.fr/tableciqual/index.htm); the rest were taken directly from the product labels of specific brands. ${ }^{c}$ Data from Monro. ${ }^{44}$ ${ }^{d}$ Glycemic index of glucose $=100$; data for glycemic index from Foster-Powell et al. ${ }^{20}$ For information, the sample size $(n$-value for means) for each food can be found in the table by Foster-Powell et al. ${ }^{20}$ When values were given without SEM, this means that they correspond to only one measurement.

“2", and "2" more processed than " 1 ". Satiety index and glycemic index were given as means \pm SEM as indicated in the original tables. ${ }^{19,20}$

\section{Results}

\section{Correlation between glycemic glucose equivalent and glycemic} index

A value for the GGE was determined for 83 foods in relation to the GI (Tables $1-3$ ). The GI and the GGE were significantly and positively correlated (Fig. $1, R_{\mathrm{S}}=0.56, P=4 \times 10^{-8}$ ). However, for low GGEs (below $15 \mathrm{~g}$ per $100 \mathrm{~g}$ ), the range of GIs is highly variable, i.e., between 6 and 100 .

\section{Relationship between processing group and glycemic impact and satiety index}

An SI was assigned to 33 foods (Tables 1-3). The SI is significantly and inversely correlated with the degree of processing (Fig. 2, $R_{\mathrm{S}}=-0.60, P=0.0002$ ). Thus, the more the food is processed, the less satiating it tends to be.

A GGE value was determined for 89 foods (Tables 1-3). The GGE is significantly and positively correlated with the processing group (Fig. 3, $R_{\mathrm{S}}=0.45, P=8 \times 10^{-6}$ ). Therefore, the more a food is processed, the higher the GGE tends to be. 




Fig. 1 Relationship between GGE and GI ( $n=83$ foods).

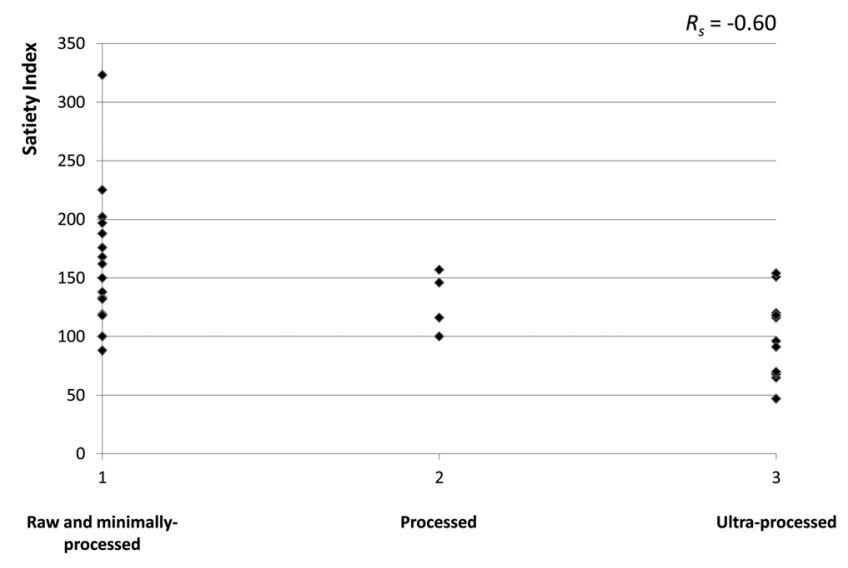

Fig. 2 Relationship between satiety index and processing groups ( $n=$ 33 foods).

Based on 89 foods, the GI, unlike the GGE, is not significantly correlated with the processing group (Fig. $4, R_{\mathrm{S}}=0.17$, $P=0.1166)$.

\section{Relationship between glycemic glucose equivalent and satiety} index

Finally, based on 21 foods (Tables 1-3), the GGE is significantly and inversely correlated with the SI (Fig. $5, R_{\mathrm{S}}=-0.58$, $P=0.0006)$. Therefore, foods with higher GGE content tend to be less satiating.

\section{Discussion}

The aim of this study was to analyze the relationship among the glycemic response, the satiety potential and the degree of processing of 98 ready-to-eat foods. My hypothesis was that the most processed foods are the least satiating and the higher the glycemic response. I also wanted to investigate the relationship between the GI and the GGE to investigate whether the GGE is a better choice than the GI for evaluating the degree of food processing. The GI is currently used primarily by dieticians to

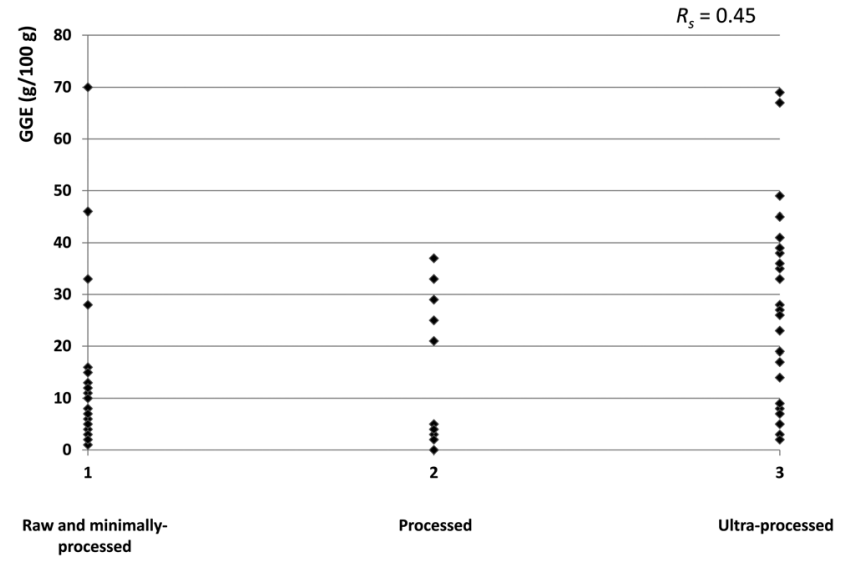

Fig. 3 Relationship between GGE and processing groups ( $n=89$ foods).

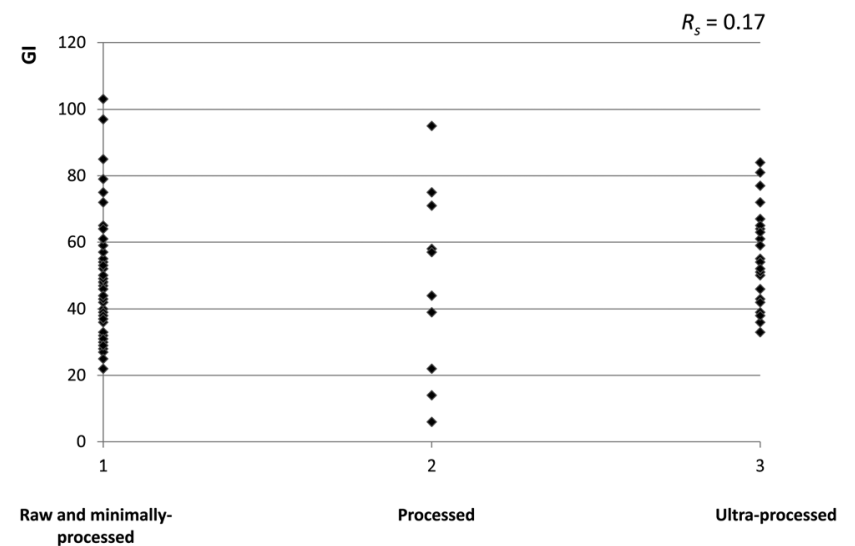

Fig. 4 Relationship between Gl and processing groups ( $n=89$ foods).

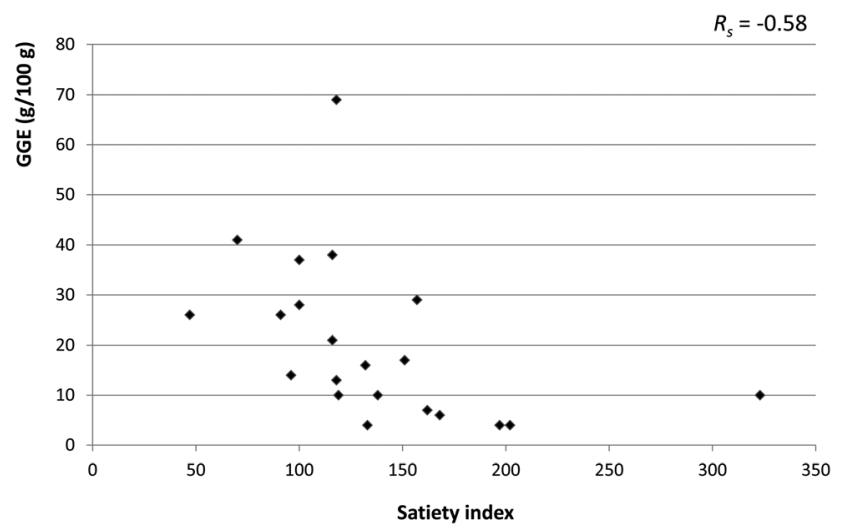

Fig. 5 Relationship between GGE and satiety index ( $n=21$ foods).

advise their diabetic patients. In the present study, the values of the GGE, GI and SI were determined from various tables, where possible, for each food. ${ }^{19,20,44}$ Then, the data were correlated. 
Although the number of foods is further reduced, the results confirmed my hypothesis and showed strong correlations between the GGE, the SI and the degree of food processing, whereas the GI is not correlated with the degree of processing. Thus, the more the food is processed, the higher the GGE and the lower its SI. This is therefore the first study emphasizing significant correlations between the degree of processing with satiety and glycemic potentials among 98 foods.

These results are in agreement with those of satiety studies on certain foods or complex diets. For example, Haber et al. showed in 10 healthy male and female volunteers that the more an apple is unstructured (whole versus puréed versus juice), the less satiating it is three hours after consumption. ${ }^{24}$ Similarly, Flood-Obbagy and Rolls showed that whole apple increased satiety more than applesauce or apple juice, addition of naturally occurring levels of fiber to juice not enhancing satiety; ${ }^{45}$ and Gustafsson et al. reported a significantly lower glycemic response and a significantly higher satiety score with a raw carrot compared to carrots cooked in a microwave for 10 healthy volunteers. ${ }^{22}$ Besides, in 36 healthy adult women, Moorhead et al. reported that, compared to a meal containing the nutrients of the carrot (i.e., no matrix and no fibers), meals including whole or mashed puréed carrots resulted in significantly higher satiety over 3.5 hours after consumption. ${ }^{23}$ In addition to the structure effect, Haber et al. ${ }^{24}$ and Moorhead et $a .^{23}$ specifically related satiety to the presence or absence of the fiber fraction.

Our findings point in the same direction as a study conducted in 2009 in our laboratory in which we showed in 11 healthy volunteers that eating a less processed cereal breakfast (pre-fermented wheat flakes, not steamed and with less sucrose) resulted in significantly higher satiety over 3 hours compared to conventional and more processed wheat flakes. ${ }^{46}$ Finally, it was shown in 14 adults with impaired glucose tolerance who consumed a breakfast ( $75 \mathrm{~g}$ available carbohydrate) including either whole almonds, almond butter, defatted almond flour, almond oil or no almonds that whole almonds led to the most attenuated and delayed glycemic response, continuing throughout the day, as well as to the strongest feeling of satiety. ${ }^{47}$

In the same way, on an equal-calorie basis $(\approx 1600 \mathrm{~kJ})$, a recent study showed in 24 healthy adult subjects that a Paleolithic diet $(718 \mathrm{~g})$, based on minimally processed foods that therefore retained their structure more or less intact, was approximately 4 times more satiating than the reference control diet ( $248 \mathrm{~g}$ ) based on white rice and containing 3 times less fiber and 19 times less total polyphenols. ${ }^{48}$ However, the glycemic and insulinemic responses differed little between these two diets.

Concerning bread, one of our basic staple foods, studies show that the less processed breads that are denser and/or contain more or less intact grains have a higher satiating potential than typical white bread, ${ }^{49,50}$ which demonstrates the effect of the physical structure of that food on satiety.

Furthermore, our results show that, while the GGE is significantly correlated with processing groups, the GI is not.
Although the number of foods analyzed is still limited, this finding suggests that the GGE would be linked more closely to food structure than the GI and therefore would better reflect the impact on it of processing.

These results show a clear link between the degree of processing, the satiating potential and the glycemic impact of foods, which is in agreement with previous literature. Therefore, in the absence of SI data, the GGE and processing group (easier and more readily determined) constitute two valuable indices for choosing foods, i.e., favoring processing groups 1 (MPF) and 2 (PF) with GGE less than $20 \mathrm{~g}$ per $100 \mathrm{~g}$ of food. Obviously, these associations need to be confirmed for an even greater number of foods.

The physical and structural characteristics of the food matrix are therefore key players in health food potential beyond nutritional composition. ${ }^{51}$ In other words, for the same nutritional composition, two different foods may give very different glycemic and satiety responses, with particularly important implications for diabetic individuals, which suggests that we should encourage complex natural and minimally processed foods over highly unstructured foods when choosing foods with low glycemic response. ${ }^{10}$ Our results also showed that the satiating potential of a food should be a new property considered in formulating or processing foods.

Pragmatically, since GGE values are significantly correlated with both degree of processing (i.e., technological groups of the NOVA classification) and SI values, and since SI values are long and difficult to measure in humans, the use of GGE as a food component on labelling (in $\mathrm{g}$ per $100 \mathrm{~g}$ ) might be a first rough and indirect reflection of the food satiety potential and degree of processing. Otherwise, based on values from nutrients that have been shown experimentally to have the greatest impact on satiety, a Fullness Factor ${ }^{\mathrm{TM}}$ has been developed to calculate the satiating effect of a food, including protein, fat, fiber and energy content (see at: http://nutritiondata.self.com/ topics/fullness-factor). Therefore, beyond the only nutrient composition, indicating GGE (g per $100 \mathrm{~g}$ ), Fullness Factor ${ }^{\mathrm{TM}}$ and NOVA group on food labelling or packaging would be an important first step to help large public better choosing healthier foods in a simple way.

The main limitation of this study was the number of foods tested. However, all the main food groups were represented (i.e., fruits, vegetables, legumes, cereals, nuts, dairy, meats and snacks), and the chosen foods are quite representative of a typical western diet. In addition, the three technological groups all contained an adequate number of foods. Another limitation was the small number of SI values (given for only 38 foods), ${ }^{19}$ which restricts the generalizability of the correlations with SI and other data. For example, the relationship between the GGE and SI, even if significantly correlated, is based on only 21 foods, and this combination therefore needs to be validated with a wider variety of foods. Finally, the NOVA classification is based on degree of processing and end use (e.g., ingredient) rather than on structure per se, which might contribute to the large amount of scatter in the data. If the foods were to be classified using a more fine-grained system specifi- 
cally related to food structure, rather than to degree of processing - that is generally associated with loss of food structure the correlations would probably have been stronger. Unfortunately, to the best of my knowledge, such a database relative to physical parameters of food structure - notably as a function of processing - does not yet exist worldwide. Such quantified food structure parameters might be then correlated with the degree of processing, e.g., hardness, softness, porosity, fragmentability and/or starch cristallinity, among others. In the end, this may also provide more useful data for the use in dietary management of glycaemic impact and satiety.

In conclusion, the main result of this study demonstrates the important role played by the structure of a food on its health characteristics, which is particularly useful in helping diabetic individuals to choose protective foods rather than basing a choice simply on GI. However, the implications can also extend towards prevention of other chronic diseases for all consumers. Otherwise, because degree of processing may not always be apparent to consumers making food choices, this paper again shows why a qualitative classification based on processing, such as NOVA classification, is needed for healthy food choices to be made.

\section{Conflict of interest}

None.

\section{Abbreviations}

GGE Glycemic glucose equivalent

GI Glycemic index

HOMA-IR Homeostasis model assessment of insulin resistance

MPF Raw and minimally processed foods

PF Processed foods

SI Satiety index

UPF Ultra-processed foods

\section{Acknowledgements}

I acknowledge the Société Francophone du Diabète Paramédical (SFD Paramédical, Paris, France) and the French Association of Nutritionist Dieticians (AFDN, Paris, France) for supplying the list of foods consumed by diabetic individuals.

\section{References}

1 K. Esposito, C. M. Kastorini, D. B. Panagiotakos and D. Giugliano, Metab. Syndr. Relat. Disord., 2010, 8, 471-476.

2 A. Alhazmi, E. Stojanovski, M. McEvoy and M. L. Garg, J. Hum. Nutr. Diet., 2014, 27, 251-260.

3 E. Koloverou, K. Esposito, D. Giugliano and D. Panagiotakos, Metabolism, 2014, 63, 903-911.
4 C. T. McEvoy, C. R. Cardwell, J. V. Woodside, I. S. Young, S. J. Hunter and M. C. McKinley, J. Acad. Nutr. Diet., 2014, 114, 1759-1775.

5 L. Schwingshackl, B. Missbach, J. Koenig and G. Hoffmann, Public Health Nutr., 2015, 18, 1292-1299.

6 Y. Yokoyama, N. D. Barnard, S. M. Levin and M. Watanabe, Cardiovasc. Diagn. Ther., 2014, 4, 373-382.

7 C. M. Kastorini, H. J. Milionis, K. Esposito, D. Giugliano, J. A. Goudevenos and D. B. Panagiotakos, J. Am. Coll. Cardiol., 2011, 57, 1299-1313.

8 A. J. Nordmann, K. Suter-Zimmermann, H. C. Bucher, I. Shai, K. R. Tuttle, R. Estruch and M. Briel, Am. J. Med., 2011, 124, 841-851.

9 A. Fardet and Y. Boirie, Nutr. Rev., 2014, 72, 741-762.

10 A. Fardet, Méd. Mal. Métab., 2014, 8, 608-611.

11 A. Fardet, E. Rock, J. Bassama, P. Bohuon, P. Prabhasankar, C. Monteiro, J.-C. Moubarac and N. Achir, Adv. Nutr., 2015, 6, 629-638.

12 D. Lioger, A. Fardet and C. Remesy, Cah. Nutr. Diet., 2007, 42, 309-319.

13 Q. Sun, D. Spiegelman, R. M. van Dam, M. D. Holmes, V. S. Malik, W. C. Willett and F. B. Hu, Arch. Intern. Med., 2010, 170, 961-969.

14 J. C. Moubarac, A. P. B. Martins, R. M. Claro, R. B. Levy, G. Cannon and C. A. Monteiro, Public Health Nutr., 2013, 16, 2240-2248.

15 M. L. Louzada, A. P. Martins, D. S. Canella, L. G. Baraldi, R. B. Levy, R. M. Claro, J. C. Moubarac, G. Cannon and C. A. Monteiro, Rev. Saude Publica, 2015, 49, 38.

16 M. L. Louzada, A. P. Martins, D. S. Canella, L. G. Baraldi, R. B. Levy, R. M. Claro, J. C. Moubarac, G. Cannon and C. A. Monteiro, Rev. Saude Publica, 2015, 49, 1-8.

17 C. M. Luiten, I. H. Steenhuis, H. Eyles, C. Ni Mhurchu and W. E. Waterlander, Public Health Nutr., 2016, 19, 530-538.

18 R. M. Bielemann, J. V. Santos Motta, G. C. Minten, B. L. Horta and D. P. Gigante, Rev. Saude Publica, 2015, 49, 28-28.

19 S. H. Holt, J. C. Miller, P. Petocz and E. Farmakalidis, Eur. J. Clin. Nutr., 1995, 49, 675-690.

20 K. Foster-Powell, S. H. Holt and J. C. Brand-Miller, Am. J. Clin. Nutr., 2002, 76, 5-56.

21 K. Foster-Powell and J. B. Miller, Am. J. Clin. Nutr., 1995, 62, 871S-890S.

22 K. Gustafsson, N. G. Asp, B. Hagander and T. Schweizer, Int. J. Food Sci. Nutr., 1995, 46, 3-12.

23 S. A. Moorhead, R. W. Welch, M. Barbara, E. Livingstone, M. McCourt, A. A. Burns and A. Dunne, Br. J. Nutr., 2006, 96, 587-595.

24 G. B. Haber, K. W. Heaton, D. Murphy and L. F. Burroughs, Lancet, 1977, 2, 679-682.

25 D. J. A. Jenkins, T. M. S. Wolever, R. H. Taylor, H. Barker, H. Fielden, J. M. Baldwin, A. C. Bowling, H. C. Newman, A. L. Jenkins and D. V. Goff, Am. J. Clin. Nutr., 1981, 34, 362-366.

26 J. Salmeron, J. E. Manson, M. J. Stampfer, G. A. Colditz, A. L. Wing and W. C. Willett, JAMA, J. Am. Med. Assoc., 1997, 277, 472-477. 
27 J. Salmeron, A. Ascherio, E. B. Rimm, G. A. Colditz, D. Spiegelman, D. J. Jenkins, M. J. Stampfer, A. L. Wing and W. C. Willett, Diabetes Care, 1997, 20, 545-550.

28 J. A. Monro and M. Shaw, Am. J. Clin. Nutr., 2008, 87, 237S243S.

29 J. A. Monro, Asia Pac. J. Clin. Nutr., 2002, 11, 217-225.

30 F. Rauber, P. D. B. Campagnolo, D. J. Hoffman and M. R. Vitolo, Nutr., Metab. Cardiovasc. Dis., 2015, 25, 116122.

31 L. F. Tavares, S. C. Fonseca, M. L. Garcia Rosa and E. M. Yokoo, Public Health Nutr., 2012, 15, 82-87.

32 D. S. Canella, R. B. Levy, A. P. B. Martins, R. M. Claro, J. C. Moubarac, L. G. Baraldi, G. Cannon and C. A. Monteiro, PLoS One, 2014, 9, e92752.

33 M. L. Louzada, L. G. Baraldi, E. M. Steele, A. P. Martins, D. S. Canella, J. C. Moubarac, R. B. Levy, G. Cannon, A. Afshin, F. Imamura, D. Mozaffarian and C. A. Monteiro, Prev. Med., 2015, 81, 9-15.

34 P. V. L. Moreira, L. G. Baraldi, J.-C. Moubarac, C. A. Monteiro, A. Newton, S. Capewell and M. O'Flaherty, PLoS One, 2015, 10, e0118353.

35 J.-C. Moubarac, D. C. Parra, G. Cannon and C. A. Monteiro, Curr. Obes. Rep., 2014, 3, 256-272.

36 C. A. Monteiro, R. B. Levy, R. M. Claro, I. R. R. de Castro and G. Cannon, Cad. Saúde Pública, 2010, 26, 2039-2049.

37 Ministry of Health of Brazil, Primary Health Care Department, Dietary guigelines for the Brazilian population, Secretariat of Health Care, São Paulo, 2014.
38 C. A. Monteiro, G. Cannon, R. B. Levy, J.-C. Moubarac, P. Jaime, A. P. Martins, D. Canella, M. Louzada and D. Parra, World Nutr., 2016, 7, 28-38.

39 C. A. Monteiro, G. Cannon and J.-C. Moubarac, World Nutr., 2014, 5, 140-168.

40 C. A. Monteiro, J.-C. Moubarac, G. Cannon, S. W. Ng and B. Popkin, Obes. Rev., 2013, 14, 21-28.

41 C. A. Monteiro, R. B. Levy, R. M. Claro, I. R. R. de Castro and G. Cannon, Public Health Nutr., 2011, 14, 5-13.

42 C. A. Monteiro, World Nutr., 2010, 1, 237-269.

43 C. A. Monteiro, Public Health Nutr., 2009, 12, 729-731.

44 J. Monro, Glycaemic Glucose Equivalents in New Zealand Foods, New Zealand Institute for Plant \& Food Research, 2004.

45 J. E. Flood-Obbagy and B. J. Rolls, Appetite, 2009, 52, 416422.

46 D. Lioger, A. Fardet, P. Foassert, M.-J. Davicco, J. Mardon, B. Gaillard-Martinie and C. Remesy, J. Am. Coll. Nutr., 2009, 28, 30-36.

47 A. Mori, R. Considine and R. Mattes, Nutr. Metab., 2011, 8, 6. 48 H. F. J. Bligh, I. F. Godsland, G. Frost, K. J. Hunter, P. Murray, K. MacAulay, D. Hyliands, D. C. S. Talbot, J. Casey, T. P. J. Mulder and M. J. Berry, Br. J. Nutr., 2015, 113, 574-584.

49 J. Keogh, F. Atkinson, B. Eisenhauer, A. Inamdar and J. Brand-Miller, Appetite, 2011, 57, 707-710.

50 P. Burton and H. J. Lightowler, Br. J. Nutr., 2006, 96, 877882.

51 A. Fardet, Food Funct., 2015, 6, 363-382. 